\title{
Microscopic analysis of enzyme activity, mitochondrial distribution and hydrogen peroxide in two-cell rat embryos
}

\author{
H. Matsumoto, N. Shoji, S. Sugawara, M. Umezu and E. Sato \\ Department of Animal Sciences, Faculty of Agriculture, Tohoku University, \\ 1-1 Tsutsumidori-Amamiyamachi, Aoba-ku, Sendai 981-8555, Japan
}

\begin{abstract}
A developmental block is induced by phosphate in rat embryos at the late two-cell stage. The present study was designed to examine the energy metabolism of rat two-cell blocked and non-blocked embryos. Enzyme activity was measured in individual embryos by histochemical techniques. The activities of malate dehydrogenase, isocitrate dehydrogenase, lactate dehydrogenase, pyruvate dehydrogenase, glyceraldehyde-3-phosphate dehydrogenase, glutamate dehydrogenase, glucose-6-phosphate dehydrogenase, glucose-6-phosphatase, and phosphorylase did not differ among non-blocked and blocked embryos. However, the activity of succinate dehydrogenase was significantly decreased in blocked embryos compared with non-blocked embryos. In blocked embryos, cytochrome oxidase activity was distributed homogeneously, but was located at the perinuclear region in non-blocked embryos. Active mitochondrial organization was visualized using the fluorescent probe rhodamine 123 and laser scanning confocal microscopy. In both non-blocked and blocked embryos, mitochondria were distributed homogeneously. The concentration of $\mathrm{H}_{2} \mathrm{O}_{2}$ measured fluorometrically in embryos cultured without phosphate did not change significantly during the culture period, but decreased in embryos cultured with phosphate. The timing corresponded to the occurrence of the two-cell block. In summary, these results suggest that the developmental block in rat two-cell embryos is induced by disturbance of mitochondrial energy metabolism.
\end{abstract}

\section{Introduction}

Mammalian embryos cultured in vitro tend to show developmental arrest at a stage characteristic to each species. Such a 'developmental block' was reported in rat embryos at the two-cell to four-cell stage (Folstad et al., 1969; Mayer and Fritz, 1974) and occurred in the presence of inorganic phosphate $\left(\mathrm{P}_{\mathrm{i}}\right)$ (Miyoshi et al., 1994; Matsumoto and Sugawara, 1995). At the early two-cell stage, rat embryos are not affected by exposure to a medium containing $\mathrm{P}_{\mathrm{j}}$ (Matsumoto and Sugawara, 1995), but development beyond the four-cell stage is decreased at $18 \mathrm{~h}$ and inhibited at $21 \mathrm{~h}$ of culture (Matsumoto and Sugawara, 1995).

A study of energy metabolism may help to explain the reasons for suboptimal development because the energy substrate composition of culture media is critical for embryos to achieve developmental competence (Chatot et al., 1989; McKiernan et al., 1991; Lawitts and Biggers, 1992; Conaghan et al., 1993). In hamsters, embryos cultured in medium devoid of glucose and inorganic phosphate $\left(\mathrm{Glu} / \mathrm{P}_{\mathrm{i}}\right)$ are able to overcome the two-cell block (Schini and Bavister, 1988). It has been suggested that the presence of $\mathrm{Glu} / \mathrm{P}_{\mathrm{i}}$ stimulates glycolysis and suppresses oxidative phosphorylation (Koobs, 1972) in this species by altering the balance between cytosolic and mitochondrial metabolism (Seshagiri and Bavister, 1991). Moreover, it is possible that $\mathrm{Glu} / \mathrm{P}_{\mathrm{i}}$ directly damages the mitochondria, making embryos dependent on glycolytic activity, which may be

Received 1 August 1997. inadequate for complete development in vitro (Barnett and Bavister, 1996a). Indeed, the organization of active mitochondria is disturbed in blocked mouse (Muggleton-Harris and Brown, 1988) and hamster embryos (Barnett and Bavister, 1996b).

There is now considerable evidence that oxygen free radicalinduced cellular dysfunction contributes to developmental blocks (Noda et al., 1989; Nasr-Esfahani et al., 1990; Goto et al., 1992; Umaoka et al., 1992; Li and Foote, 1993; Natsuyama et al., 1993). For example, Nasr-Esfahani et al. (1990) reported that intracellular hydrogen peroxide $\left(\mathrm{H}_{2} \mathrm{O}_{2}\right)$ concentrations are higher in two-cell mouse embryos cultured in vitro than in vivo.

Therefore, the energy metabolism of two-cell, non-blocked and blocked rat embryos was examined. Enzyme activities were measured in individual embryos using histochemical techniques. Active mitochondrial organization was detected using the fluorescent probe rhodamine 123 and laser scanning confocal microscopy. Intracellular $\mathrm{H}_{2} \mathrm{O}_{2}$ concentrations in twocell rat embryos were quantified by a fluorometric method.

\section{Materials and Methods}

\section{Animals}

Wistar rats housed with exposure to light between $06: 00 \mathrm{~h}$ and 18:00 h, bred and maintained in our laboratory, were used. The stage of the oestrous cycle was monitored by examination of vaginal smears. At pro-oestrus, females were placed with 
males for mating, and the next morning was designated as day 1 of pregnancy if a vaginal plug or spermatozoa in the vaginal smear were detected.

\section{Culture media}

The basal culture medium used in this study was hamster embryo culture medium- 1 (HECM-1) (Schini and Bavister, 1988) with modifications (mHECM-I) and containing $5.56 \mathrm{mmol}$ glucose $\mathrm{I}^{-1}, 4 \mu \mathrm{g}$ phenol red $\mathrm{ml}^{-1}, 100$ iu penicillin $\mathrm{ml}^{-1}, \quad 0.1 \mathrm{mg}$ streptomycin $\mathrm{ml}^{-1}$ and $0.5 \mathrm{mg}$ polyvinyl alcohol $\mathrm{ml}^{-1}$, and lacked phosphate $\left(\mathrm{P}_{\mathrm{i}}(-)\right)$. The medium induced to two-cell block contained $1.19 \mathrm{mmol} \mathrm{KH}_{2} \mathrm{PO}_{4} \mathrm{l}^{-1}$ $\left(\mathrm{P}_{\mathrm{i}}(+)\right)$.

\section{Embryo collection}

Early two-cell embryos were collected at 11:00 h on day 2 by flushing with mHECM-1. Embryos were washed three times with $\mathrm{mHECM}-1$ and then placed in the medium in which they were to be cultured $\left(\mathrm{P}_{\mathrm{i}}(-)\right.$ or $\left.\mathrm{P}_{\mathrm{i}}(+)\right)$. All embryos were cultured in $100 \mu \mathrm{l}$ drops under a layer of mineral oil in a humidified atmosphere of $5 \% \mathrm{CO}_{2}$ in air at $37.5^{\circ} \mathrm{C}$.

\section{Histochemical characteristics of enzyme activities}

The distributions and activities of enzymes in non-blocked and blocked embryos were measured histochemically, after culture for $20-24 \mathrm{~h}$ in $\mathrm{P}_{\mathrm{i}}(-)$ or $\mathrm{P}_{\mathrm{i}}(+)$ medium. Malate dehydrogenase, isocitrate dehydrogenase, lactate dehydrogenase, glucose-6-phosphate dehydrogenase and glutamate dehydrogenase activities (dependent on NAD or NADP type) were detected by the method of Barka and Anderson (1963). Pyruvate dehydrogenase, glyceraldehyde-3-phosphate dehydrogenase, glucose-6-phosphatase, phosphorylase, cytochrome oxidase and succinate dehydrogenase activities were detected by the method of Ferguson (1966), Himmelhoch-Karnovsky (1961), Wachstein and Meisel (1956), Takeuchi (1962), Burstone (1962) and Nachlas et al. (1957), respectively. For controls, embryos were incubated in a medium devoid of substrate. Stained embryos were placed in the centre of four Vaseline spots on a glass slide. A cover slip was then placed carefully onto the Vaseline spots and pressed gently to anchor the embryos between the cover slip and the slide. Mounted embryos were observed under a light microscope (Olympus, $\mathrm{BH}-2$ ). All assessments of enzyme staining and intensity were made by the same investigator to eliminate observer variation. The intensity of the enzyme activity was judged by the amount of deposited reaction products using the criteria of Niimura and Ishida $(1976,1978)$ and estimated on a three-point scale: strong, weak and not detectable.

\section{Distribution of active mitochondria}

Embryos were stained with Rhodamine 123 and imaged with confocal laser-scanning microscopy. Rhodamine 123
(Molecular Probes, Eugene, OR) stock solution $\left(10 \mathrm{mg} \mathrm{ml}^{-1}\right.$; dissolved in methanol) was stored at $-40^{\circ} \mathrm{C}$. Embryos were cultured for $24 \mathrm{~h}$ and then stained for $15 \mathrm{~min}$ in $10 \mu \mathrm{g}$ Rhodamine $123 \mathrm{ml}^{-1}$ in $\mathrm{mHECM}-1$ at $37.5^{\circ} \mathrm{C}$ under $5 \% \mathrm{CO}_{2}$ in air. Confocal images were obtained using a Biorad MRC1024 laser scanning microscope, mounted on an Axioplan Zeiss microscope.

\section{Measurement of $\mathrm{H}_{2} \mathrm{O}_{2}$ in embryos}

The fluorometric method of Nasr-Esfahani et al. (1990) and Goto et al. (1993) with modifications was used to measure the concentration of $\mathrm{H}_{2} \mathrm{O}_{2}$ in embryos. A $1 \mathrm{mmol} 1^{-1}$ stock solution of $2^{\prime}, 7^{\prime}$-dichlorodihydrofluorescin diacetate (DCHDFA; Molecular Probes) was prepared in acetone before the start of each experiment and kept in the dark. The stock solution was diluted in MHECM-1 to the experimental concentration $\left(10 \mu \mathrm{mol} \mathrm{1}^{-1}\right)$. At intervals of $6 \mathrm{~h}$, embryos were incubated for $30 \mathrm{~min}$ in $10 \mu \mathrm{mol}$ DCHDFA $\mathrm{I}^{-1}$ at $37.5^{\circ} \mathrm{C}$ under $5 \% \mathrm{CO}_{2}$ in air. After reaction, embryos were washed in mHECM-1 to remove traces of dye and placed in small chambers containing mHECM- 1 and covered with a coverslip. The fluorescence emissions of single embryos were measured immediately with $\lambda$ ex: $460 \mathrm{~nm}$ and $\lambda \mathrm{em}$ : $530 \mathrm{~nm}$, using a microscopic fluorometer using CAM-220 (Japan Spectroscopic Co., Tokyo, Japan).

\section{Statistical analysis}

Histochemical characteristics of enzyme activities were analysed using the Mann-Whitney U test. The concentrations of $\mathrm{H}_{2} \mathrm{O}_{2}$ were analysed by ANOVA. Differences in group means were detected by Fisher's protected least significant difference.

\section{Results}

\section{Histochemical characteristics of enzyme activities}

In both non-blocked and blocked embryos, there were strong activities of malate dehydrogenase, isocitrate dehydrogenase and lactate dehydrogenase, and weak activities of glutamate dehydrogenase (dependent on NAD or NADP type). Pyruvate dehydrogenase, glyceraldehyde-3-phosphate dehydrogenase and glucose-6-phosphatase could not be detected. Weak activity of phosphorylase was detected in both non-blocked (94\%) and blocked $(94 \%)$ embryos. Strong and weak activity of glucose-6-phosphate dehydrogenase was detected in non-blocked (strong and weak: 42 and 58\%, respectively) and in blocked (strong and weak: 40 and 60\%, respectively) embryos. The overall activity of these enzymes did not differ between non-blocked and blocked embryos (Figs 1 and 2; Table 1). However, succinate dehydrogenase and cytochrome oxidase activities differed between non-blocked and blocked embryos. The activity of succinate dehydrogenase

Fig. 1. Histochemical characteristics of enzyme activities in developmentally non-blocked $(a, c, e, g, i)$ and blocked $(b, d, f, h, j)$ rat embryos. $(a, b)$ Strong activity of malate dehydrogenase. (c,d) Strong activity of isocitrate dehydrogenase. (e,f) Strong activity of lactate dehydrogenase. (g,h) Activity of pyruvate dehydrogenase not detectable. $(\mathrm{i}, \mathrm{j})$ Activity of glyceraldehyde-3-phosphate dehydrogenase not detectable. Scale bar represents $30 \mu \mathrm{m}$. 
(a)

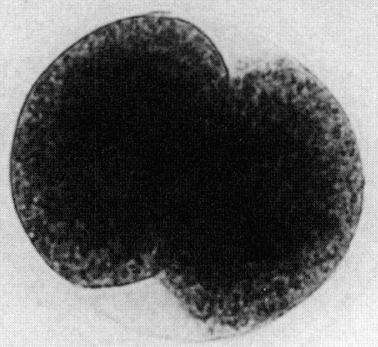

(c)

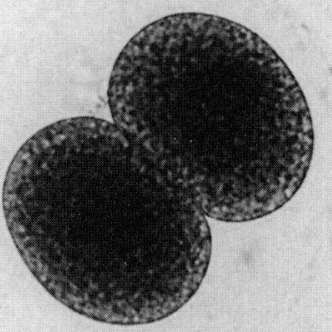

(e)
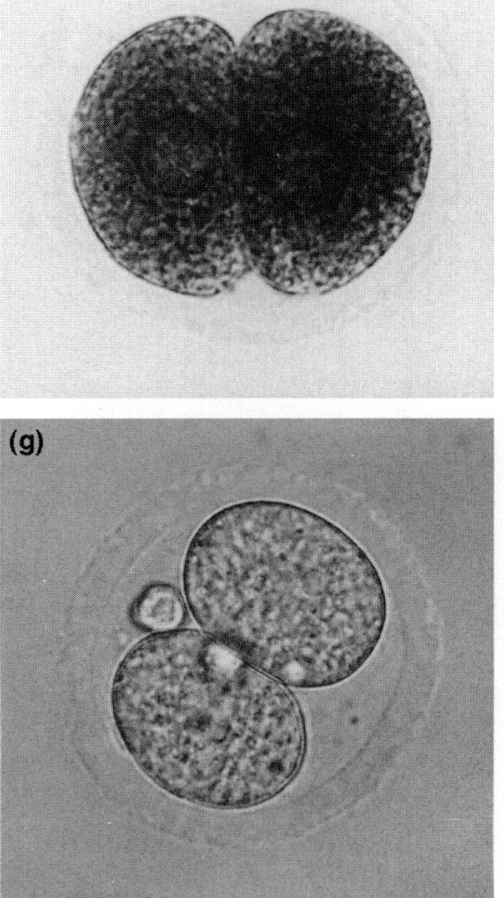

(i)

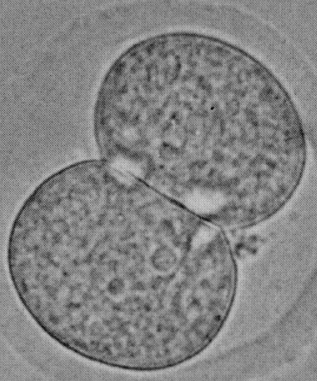

(b)

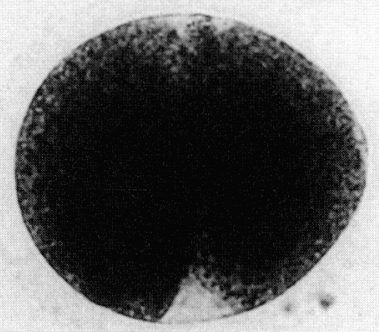

(d)

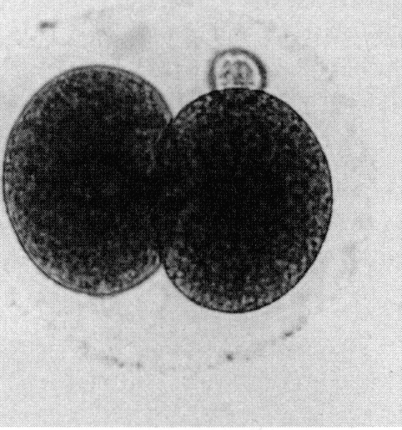

(f)
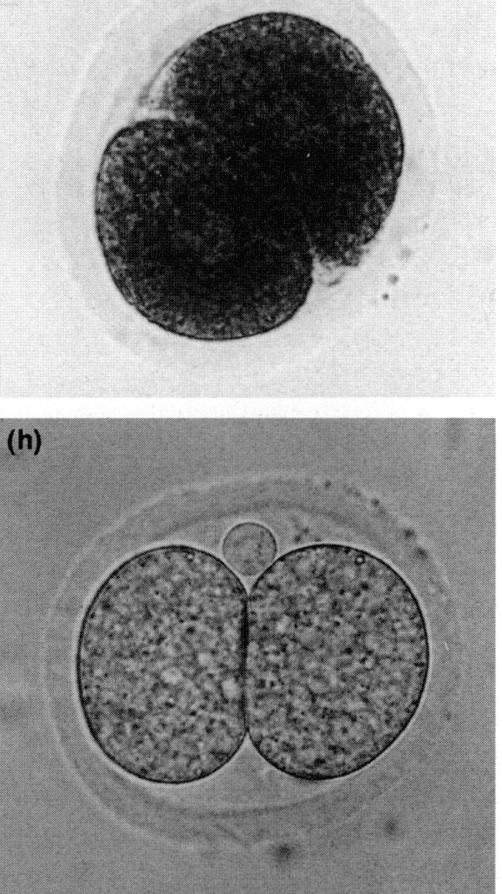

(i)

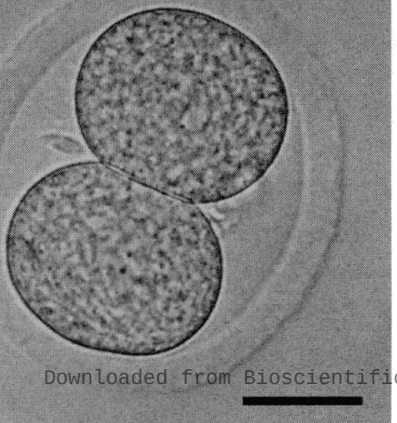



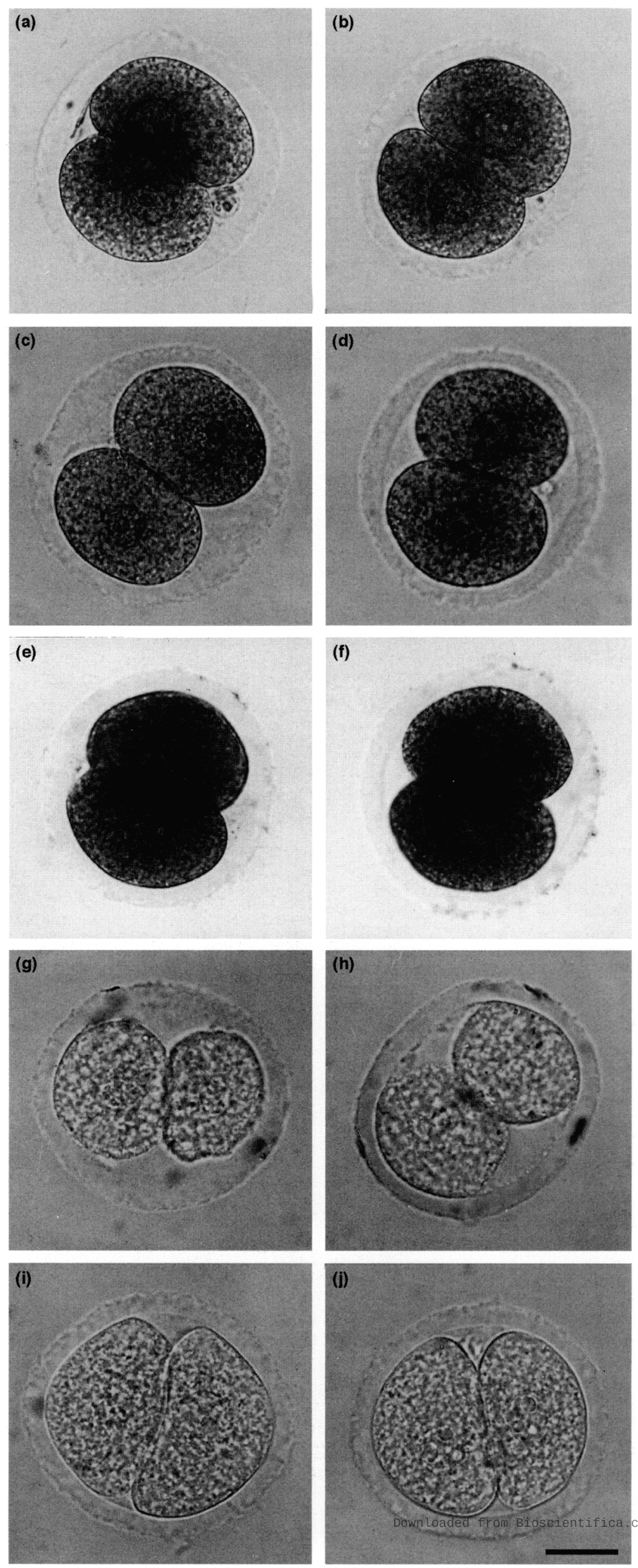
Table 1. Histochemical characteristics of enzyme activities in non-blocked and blocked rat two-cell embryos

\begin{tabular}{|c|c|c|c|c|c|c|c|c|c|c|c|c|}
\hline \multirow{3}{*}{$\begin{array}{l}\text { Enzyme } \\
\text { Malate dehydrogenase }\end{array}$} & \multicolumn{6}{|c|}{ Non-blocked embryos } & \multicolumn{6}{|c|}{ Blocked embryos } \\
\hline & \multirow[b]{2}{*}{26} & \multicolumn{2}{|c|}{ ND } & \multicolumn{2}{|c|}{ Weak } & Strong & \multirow{2}{*}{$\frac{n}{23}$} & \multicolumn{2}{|c|}{ ND } & \multicolumn{2}{|c|}{ Weak } & \multirow{2}{*}{$\begin{array}{l}\text { Strong } \\
23(100\end{array}$} \\
\hline & & 0 & (0) & 0 & (0) & $26(100)$ & & 0 & (0) & 0 & (0) & \\
\hline Isocitrate dehydrogenase & 30 & 0 & (0) & 0 & (0) & $30(100)$ & 29 & 0 & (0) & 0 & (0) & $29(100)$ \\
\hline Lactate dehydrogenase & 31 & 0 & (0) & 0 & (0) & $31(100)$ & 32 & 0 & (0) & 0 & (0) & $32(100)$ \\
\hline Pyruvate dehydrogenase & 27 & & 100) & 0 & (0) & $0 \quad(0)$ & 21 & & (100) & 0 & (0) & $0 \quad(0)$ \\
\hline Glyceraldehyde-3-phosphate dehydrogenase & 31 & 31 & 100) & & (0) & $0 \quad(0)$ & 29 & & (100) & 0 & (0) & $0 \quad(0)$ \\
\hline Glutamate dehydrogenase (NAD type) & 33 & 0 & (0) & & (100) & $0 \quad(0)$ & 34 & 0 & (0) & & 100) & $0 \quad(0)$ \\
\hline Glutamate dehydrogenase (NADP type) & 29 & 0 & (0) & 29 & (100) & $0 \quad(0)$ & 32 & 0 & (0) & & 100) & (0) \\
\hline Glucose-6-phosphate dehydrogenase & 36 & 0 & (0) & 21 & (58) & $15 \quad(42)$ & 37 & 0 & (0) & 22 & (60) & $15 \quad(40)$ \\
\hline Glucose-6-phosphatase & 26 & & 100) & 0 & (0) & $0 \quad(0)$ & 32 & & (100) & 0 & (0) & $\begin{array}{ll}0 & (0)\end{array}$ \\
\hline Phosphorylase & 32 & 30 & (94) & 2 & (6) & $0 \quad(0)$ & 32 & 30 & (94) & 2 & (6) & $0 \quad(0)$ \\
\hline Succinate dehydrogenase* & 50 & 26 & (52) & 7 & (14) & 17 (34) & 51 & 44 & (86) & 1 & (2) & $6 \quad$ (12) \\
\hline Cytochrome oxidase & 47 & 0 & (0) & 0 & (0) & $47(100)^{\dagger}$ & 38 & 0 & (0) & 0 & (0) & $38(100)$ \\
\hline
\end{tabular}

Numbers in parentheses show percentages.

ND, not detectable.

*Significant difference between non-blocked and blocked embryos $(P<0.05)$.

${ }^{\dagger}$ Enzyme activities were distributed in the perinuclear regions.

in blocked embryos (strong and weak: 12 and $2 \%$, respectively) was significantly decreased relative to non-blocked embryos (strong and weak: 34 and 14\%, respectively) (Fig. 3; Table 1; $P<0.05$ ). The activity of cytochrome oxidase was strong in both types of embryo (Fig. 4; Table 1). While strong activity for cytochrome oxidase was located at the perinuclear region in non-blocked embryos, it was distributed homogeneously in blocked embryos.

\section{Distribution of active mitochondria}

Active mitochondrial organization was imaged using the fluorescent probe Rhodamine 123 and laser scanning confocal microscopy (Fig. 5). Data were collected from 49 non-blocked embryos and 43 blocked embryos. Mitochondrial distribution was homogeneous in non-blocked embryos, cultured in $\mathrm{P}_{\mathrm{i}}(-)$. In blocked embryos, mitochondrial distribution was similarly distributed homogeneously. Fluorescence intensity did not differ between non-blocked and blocked embryos.

\section{Concentrations of $\mathrm{H}_{2} \mathrm{O}_{2}$ in embryos}

The data for $\mathrm{H}_{2} \mathrm{O}_{2}$ concentration are relative to the value for culture in $\mathrm{P}_{\mathrm{i}}(-)$ at $\mathrm{O}$ h. The concentration of $\mathrm{H}_{2} \mathrm{O}_{2}$ in the embryos incubated in $\mathrm{P}_{\mathrm{i}}(-)$ did not change significantly with time in culture, but those grown in $\mathrm{P}_{\mathrm{i}}(+)$ showed a gradual significant decrease over the culture period for more than $18 \mathrm{~h}$ (Fig. 6; $P<0.05$ ).

\section{Discussion}

Energy metabolism in non-blocking and blocking two-cell rat embryos has been examined. In a previous study, when early two-cell embryos were cultured in medium containing $P_{\mathrm{i}^{\prime}}$ development beyond the four-cell stage was decreased at $18 \mathrm{~h}$ and inhibited at $21 \mathrm{~h}$ after cultivation (Matsumoto and Sugawara, 1995) whereas the majority of embryos cultured in $\mathrm{P}_{\mathrm{i}}(-)$ cleaved at $24-30 \mathrm{~h}$ after cultivation. Therefore, nonblocking and blocking two-cell embryos were collected after culture for $20-24 \mathrm{~h}$ and subjected to histochemical analysis of enzyme activity and mitochondrial distribution. Succinate dehydrogenase and cytochrome oxidase, which are present in mitochondria, showed different activities in non-blocking and blocking embryos; however, the other enzymes in mitochondria: malate dehydrogenase, isocitrate dehydrogenase, pyruvate dehydrogenase and glutamate dehydrogenase, were unchanged. Moreover, no differences were demonstrated for the enzymes of other metabolic pathways: lactate dehydrogenase and glyceraldehyde-3-phosphate dehydrogenase (glycolysis), glucose-6-phosphatase and phosphorylase (glycogen metabolism) and glucose-6-phosphate dehydrogenase (pentose phosphate pathway). These results indicate that the developmental block in rat two-cell embryos is disturbed by specific enzyme activities and a specific pathway in energy metabolism in mitochondria.

Rhodamine 123, a fluorescent probe that signals the electrical potential across the inner mitochondrial membrane, was used to measure 'active' mitochondrial distribution. Mitochondria were distributed homogeneously in both non-blocked and blocked rat two-cell embryos. In mice, Muggleton-Harris and Brown (1988) found that mitochondria in normally cleaving two-cell embryos were distributed homogeneously throughout the cytoplasm of blastomeres during interphase, with specific mitochondrial translocations to the mitotic spindle being observed during cleavage. In developmentally arrested two-cell

Fig. 2. Histochemical characteristics of enzyme activities in developmentally non-blocked (a,c,e,g,i) and blocked (b,d,f,h,j) rat embryos. (a,b) Weak activity of glutamate dehydrogenase (NAD type). (c,d) Weak activity of glutamate dehydrogenase (NADP type). (e,f) Strong activity of glucose-6-phosphate dehydrogenase. (g,h) Activity of glucose-6-phosphatase not detectable. (i,j) Activity of phosphorylase not detectable. Scale bar represents $30 \mu \mathrm{m}$. 
(a)
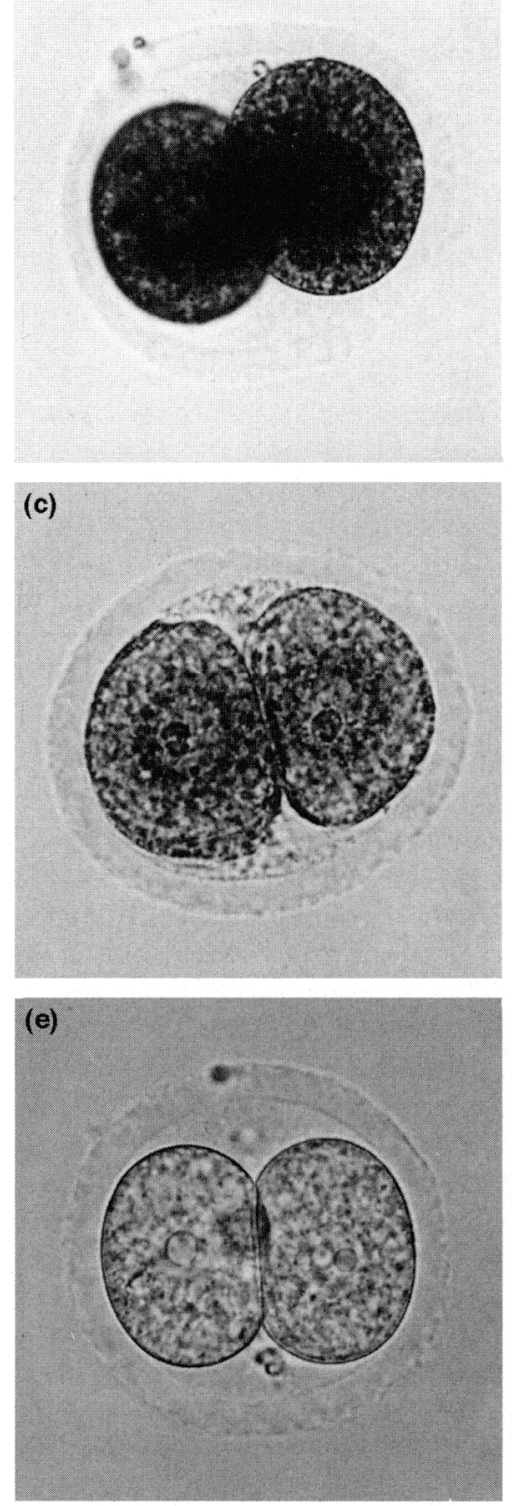

(b)

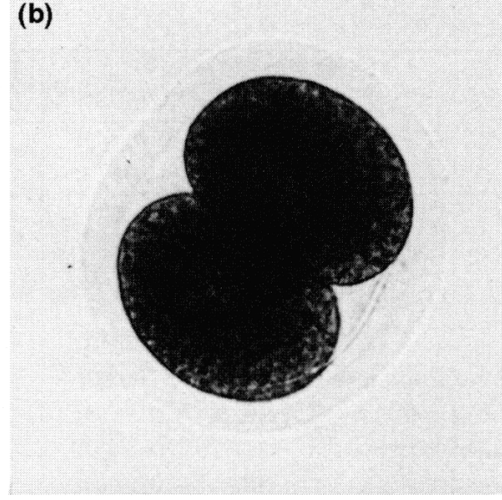

(d)

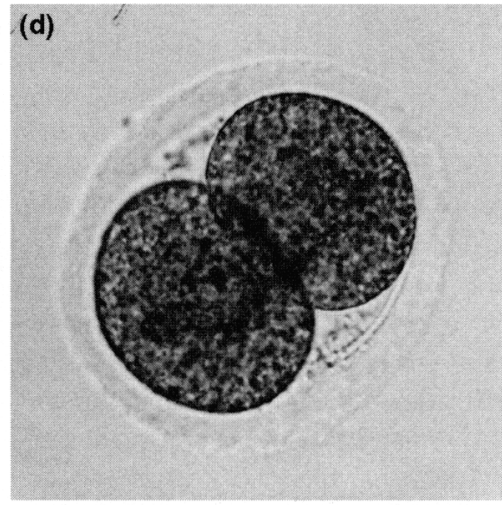

(f)

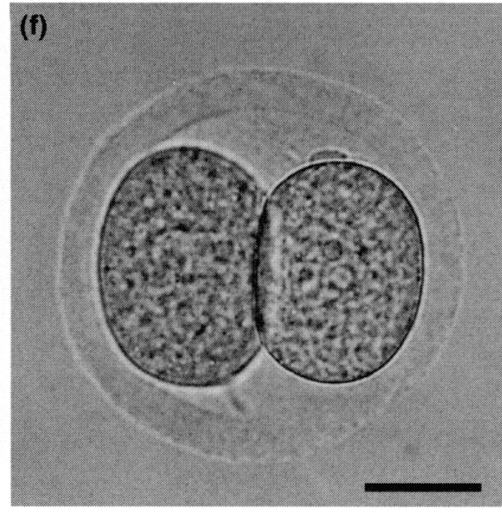

Fig. 3. Histochemical characteristics of succinate dehydrogenase activity in developmentally non-blocked $(a, c, e)$ and blocked $(b, d, f)$ rat embryos. $(a, b)$ Strong, ( $(, d)$ weak and $(e, f)$ not detectable activities. Scale bar represents $30 \mu \mathrm{m}$.

mouse embryos, the mitochondria became progressively aggregated and localized in the perinuclear region and an area of cytocortex immediately adjacent to the plasma membrane (Muggleton-Harris and Brown, 1988). In non-blocked two-cell hamster embryos, mitochondria were clustered in the perinuclear region (Barnett and Bavister, 1996b). In developmentally blocked two-cell hamster embryos, mitochondria showed no perinuclear clustering and were much more homogeneously distributed (Barnett and Bavister, 1996b). However, blocked two-cell rat embryos showed no differences in mitochondrial distribution, suggesting that such embryos have the same electrical potential across the inner mitochondrial membrane as do non-blocked embryos.
The concentration of $\mathrm{H}_{2} \mathrm{O}_{2}$ in the embryos cultured in $\mathrm{P}_{\mathrm{i}}(-)$ did not significantly change during the culture period, but gradually and significantly decreased in embryos cultured in $\mathrm{P}_{\mathrm{i}}(+)$ for more than $18 \mathrm{~h}$. This timing coincided with the developmental block in two-cell rat embryos (Matsumoto and Sugawara, 1995). At the early two-cell stage, rat embryos were not affected by exposure to a medium containing $\mathrm{P}_{\mathrm{i}}$, but in embryos cultured in medium containing $P_{\mathrm{i}}$, the development decreased at $18 \mathrm{~h}$ and was inhibited at $21 \mathrm{~h}$ after cultivation (Matsumoto and Sugawara, 1995). The decrease in $\mathrm{H}_{2} \mathrm{O}_{2}$ concentration could reflect some restricted function of the oxygen activation system, because the respiratory chain in mitochondria produces the reactive oxygen species $\left(\mathrm{H}_{2} \mathrm{O}_{2}\right)$ 
(a)

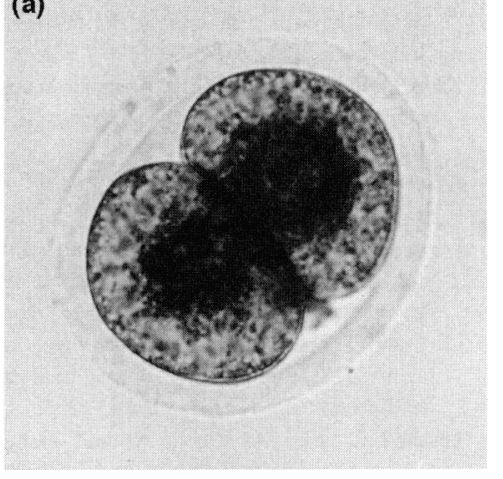

(b)

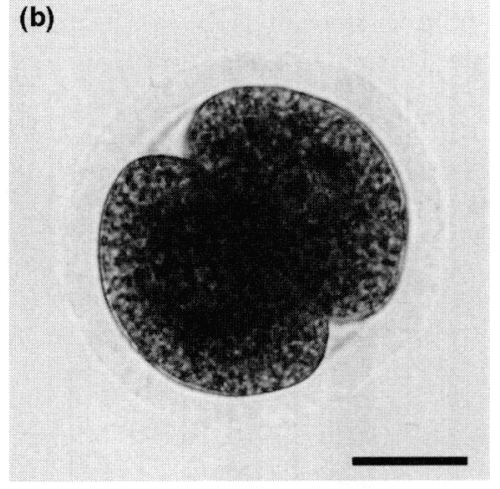

Fig. 4. Histochemical characteristics of cytochrome oxidase activity in developmentally non-blocked (a) and blocked (b) rat embryos. Activities were strong in non-blocked and blocked embryos. (a) In non-blocked embryos, cytochrome oxidase activity was strong in the perinuclear region. (b) In blocked embryos, strong activity was distributed homogeneously. Scale bar represents $30 \mu \mathrm{m}$.
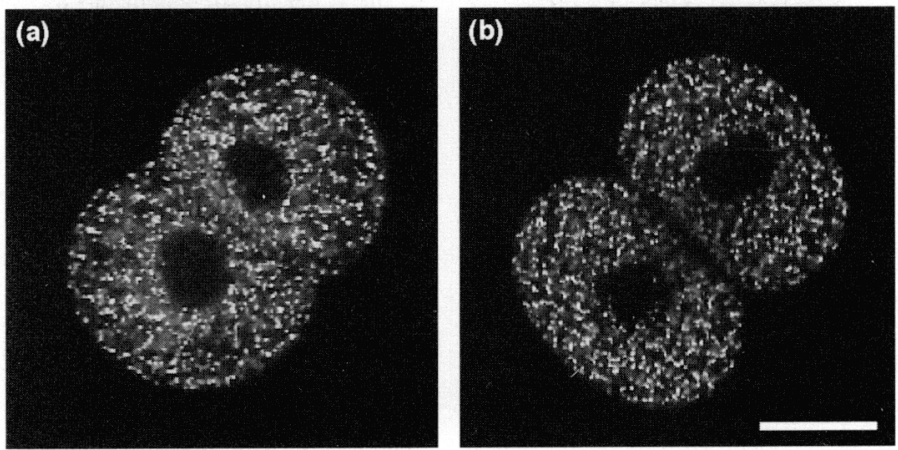

Fig. 5. Active mitochondrial organization imaged by the fluorescent probe Rhodamine 123. Mitochondrial distribution was homogeneous in both developmentally non-blocked (a) and blocked (b) rat embryos. Fluorescence intensity did not differ between non-blocked and blocked embryos. Scale bar represents $30 \mu \mathrm{m}$.

(Boveris and Chance, 1973; Loschen et al., 1974; Boveris and Cadenas, 1975; Rich and Borner, 1978).

In mouse embryos, there is evidence that oxygen free radical-induced cellular dysfunction contributes to developmental block and there is a strong association between increasing $\mathrm{H}_{2} \mathrm{O}_{2}$ concentration and the arrest (Noda et al., 1989; Nasr-Esfahani et al., 1990; Goto et al., 1992; Umaoka et al., 1992; Natsuyama et al., 1993). In rats, the rate of blastocyst formation of pronuclear embryos cultured in HECM-1 under a low oxygen concentration (5\%) was significantly greater than the value obtained under a standard oxygen concentration (20\%) (Kishi et al., 1991). However, when cultured in $20 \%$ oxygen, a large proportion of rat one-cell embryos can develop to the blastocyst stage in a chemically defined medium supplemented with amino acids and with the osmolarity adjusted to about $246 \mathrm{mmol}$ (Miyoshi et al., 1995). Therefore, oxygen radical formation may not be a major cause of developmental block in the early rat embryo.

The mechanism of the developmental block in early mammalian embryos remains one of the most intriguing aspects of embryo metabolism (Bavister, 1995; Barnett and Bavister, 1996a). The most likely biochemical explanation for the observed glucose/ $/ P_{i}$ inhibition of hamster embryo development is inadequate energy production owing to the inhibition of mitochondrial oxidative metabolism (Seshagiri and Bavister, 1991; Barnett and Bavister, 1996a). In medium containing glucose $/ \mathrm{P}_{\mathrm{i}}, \mathrm{P}_{\mathrm{i}}$ stimulates cellular glycolysis by activating three key glycolytic enzymes (hexokinase, phosphofructokinase, and glyceraldehyde-3-phosphate dehydrogenase) and possibly by relieving inhibition of hexokinase by glucose-6-phosphate ( $\mathrm{Wu}, 1965)$. Enhanced glycolysis results in the inhibition of mitochondrial respiration, a classic phenomenon first described in 1929 and known as the 'Crabtree effect' (Crabtree, 1929; Koobs, 1972). Although the activities of glyceraidehyde-3-phosphate dehydrogenase and other enzymes in glycolysis did not differ between non-blocked and blocked rat embryos, respiratory metabolism in blocked embryos was disturbed, as reflected by a reduced $\mathrm{H}_{2} \mathrm{O}_{2}$ production and an altered cytochrome oxidase activity. These results may indicate that the developmental block observed in rats is caused by the 'Crabtree effect'. 


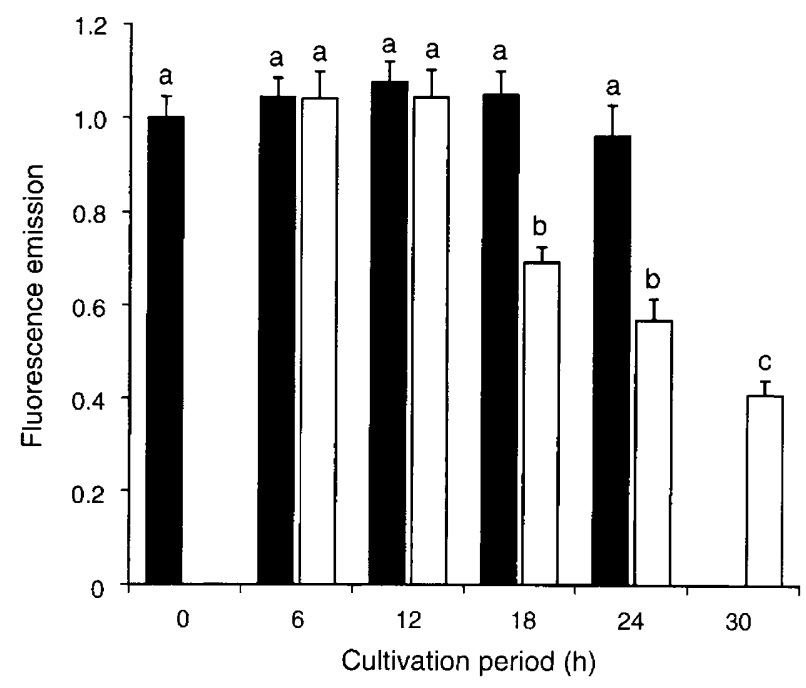

Fig. 6. Changes in production of $\mathrm{H}_{2} \mathrm{O}_{2}$ in two-cell rat embryos incubated in the absence ( $\square$ ) and presence $(\square)$ of inorganic phosphate. Results are means \pm SEM using a total of 39-62 embryos. Bars with different letters are significantly different $(P<0.05)$.

Part of this study was supported by a Grant-in-Aid for Scientific Research (number 09760248) from the Ministry of Education, Science and Culture, Japan.

\section{References}

Barka T and Anderson PJ (1963) Histochemistry - Theory, Practice and Bibliography Harper and Row Publishers, New York

Barnett DK and Bavister BD (1996a) What is the relationship between the metabolism of preimplantation embryos and their developmental competence? Molecular Reproduction and Development 43 105-133

Barnett DK and Bavister BD (1996b) Inhibitory effect of glucose and phosphate on the second cleavage division of hamster embryos: is it linked to metabolism? Human Reproduction 11 177-183

Bavister BD (1995) Culture of preimplantation embryos: facts and artifacts Human Reproduction Update 191-148

Boveris A and Chance B (1973) The mitochondrial generation of hydrogen peroxide. General properties and effect of hyperbaric oxygen Biochemical Journal 134 707-716

Boveris A and Cadenas E (1975) Mitochondrial production of superoxide anions and its relationship to the antimycin insensitive respiration FEBS Letters $\mathbf{5 4}$ 311-314

Burstone MS (1962) Enzyme Histochemistry Academic Press, New York

Chatot CL, Ziomek CA, Bavister BD, Lewis JL and Torres I (1989) An improved culture medium supports development of random-bred 1-cell mouse embryos in vivo. Journal of Reproduction and Fertility 86 679-688

Conaghan J, Handyside AH, Winston RML and Leese HJ (1993) Effects of pyruvate and glucose on the development of human preimplantation embryos in vitro. Journal of Reproduction and Fertility 99 87-95

Crabtree HG (1929) Observation on the carbohydrate metabolism of tumors Biochemical Journal 23 536-545

Ferguson MM (1966) Histochemical demonstration of pyruvate oxidase and $\alpha$-ketoglutarate oxidase Histochemie 6 185-186

Folstad L, Bennet JP and Dorfaman RI (1969) The in vitro culture of rat ova Journal of Reproduction and Fertility 18 145-146

Goto Y, Noda Y, Narimoto K, Umaoka Y and Mori T (1992) Oxidative stress on mouse embryo development in vitro. Free Radical Biology and Medicine 13 $47-53$

Goto Y, Noda Y, Mori T and Nakano M (1993) Increased generation of reactive oxygen species in embryos cultured in vitro. Free Radical Biology and Medicine $1569-75$
Himmelhoch SR and Karnovsky MJ (1961) The histochemical demonstration of glyceraldehyde-3-phosphate dehydrogenase Journal of Biophysical and Biochemical Cytology 9 573-581

Kishi J, Noda Y, Narimoto K, Umaoka Y and Mori T (1991) Block to development in cultured rat 1-cell embryos is overcome using medium HECM-1 Human Reproduction 6 1445-1448

Koobs DH (1972) Phosphate mediation of the Crabtree and Pasteur effects Science 178 127-133

Lawitts JL and Biggers JD (1992) Joint effects of sodium chloride, glutamine, and glucose in mouse preimplantation embryo culture media Molecular Reproduction and Development 31 189-194

Li J and Foote RH (1993) Culture of rabbit zygotes into blastocysts in protein-free medium with one to twenty per cent oxygen Journal of Reproduction and Fertility 98 163-167

Loschen G, Azzi A, Richter C and Flohé L (1974) Superoxide radicals as precursors of mitochondrial hydrogen peroxide FEBS Letters 42 68-72

McKiernan SH, Bavister BD and Tasca RJ (1991) Energy substrate requirements for in vitro development of hamster 1- and 2-cell embryos to the blastocyst stage Human Reproduction 6 64-75

Matsumoto H and Sugawara S (1995) Development of rat embryos at the 1- and 2-cell stage in modified HECM-1 medium, after exposure to medium that contained phosphate Journal of Reproduction and Development 41 263-269

Mayer JF, Jr and Fritz HI (1974) The culture of preimplantation rat embryos and the production of allophenic rats Journal of Reproduction and Fertility 39 1-9

Miyoshi K, Funahashi H, Okuda K and Niwa K (1994) Development of rat one-cell embryos in a chemically defined medium: effects of glucose, phosphate and osmolarity Journal of Reproduction and Fertility 100 21-26

Miyoshi K, Abeydeera LR, Okuda K and Niwa K (1995) Effects of osmolarity and amino acids in a chemically defined medium on development of rat one-cell embryos Journal of Reproduction and Fertility 103 27-32

Muggleton-Harris AL and Brown JJG (1988) Cytoplasmic factors influence mitochondrial reorganization and resumption of cleavage during culture of early mouse embryos Human Reproduction 3 1020-1028

Nachlas MM, Tsou KC, Souda ED, Cheng CS and Seligman AM (1957) Cyto. chemical demonstration of succinate dehydrogenase by the use of a new $p$-nitrophenyl substituted ditetrazole journal of Histochemistry and $C y$ tochemistry 5 420-436

Nasr-Esfahani MH, Aitken JR and Johnson MH (1990) Hydrogen peroxide levels in mouse oocytes and early cleavage stage embryos developed in vitro and in vivo. Development $109501-507$

Natsuyama S, Noda Y, Narimoto K and Mori T (1993) Role of protein supplements in the culture of mouse embryos Theriogenology 40 149-157

Niimura S and Ishida K (1976) Histochemical studies of $\Delta^{5}-3 \beta-, 20 \alpha$ - and 20ß-hydroxysteroid dehydrogenases and possible progestagen production in hamster eggs Journal of Reproduction and Fertility $\mathbf{4 8} 275-278$

Niimura S and Ishida K (1978) Histochemical demonstration of prostaglandin dehydrogenases in the uterine and chorionic epithelia of the pregnant pig Journal of Reproduction and Fertility 54 149-151

Noda Y, Matsumoto H, Mori T (1989) Superoxide dismutase overcomes 2-cell block in mouse embryos Acta Obstetrica et Gynaecolgia Japonica 41 751-752 (in Japanese)

Rich PR and Borner WD, Jr (1978) The sites of superoxide anion generation in higher plant mitochondria Archives of Biochemistry and Biophysics $\mathbf{1 8 8}$ 206-213

Schini SA and Bavister BD (1988) Two-cell block to development of cultured hamster embryos is caused by phosphate and glucose Biology of Reproduction 39 1183-1192

Seshagiri PB and Bavister BD (1991) Glucose and phosphate inhibit respiration and oxidative metabolism in cultured hamster eight-cell embryos: evidence for 'Crabtree effect' Molecular Reproduction and Development 30 105-111

Takeuchi T (1962) Histochemistry of intracellular polysaccharide synthesis Annales d'Histochimie 7 61-80

Umaoka Y, Noda Y, Narimoto K and Mori T (1992) Effects of oxygen toxicity on early development of mouse embryos Molecular Reproduction and Development 31 28-33

Wachstein $M$ and Meisel E (1956) On the histochemical demonstration of glucose-6-phosphatase Joumal of Histochemistry and Cytochemistry 4592

Wu R (1965) Control mechanisms of glycolysis in Ehrlich ascites tumor cells Journal of Biological Chemistry 240 2827-2832 